\title{
Spotlight on the psychological basis of childhood pet attachment and its implications
}

This article was published in the following Dove Press journal:

Psychology Research and Behavior Management

\section{Shelby H Wanser \\ Kristyn R Vitale \\ Lauren E Thielke \\ Lauren Brubaker \\ Monique AR Udell}

Department of Animal and Rangeland Sciences, Oregon State University,

Corvallis, OR, USA
Correspondence: Monique AR Udell Department of Animal and Rangeland Sciences, Oregon State University, II 2 Withycombe Hall, 292I SW Campus

Way, Corvallis, OR 9733I, USA

$\mathrm{Tel} / \mathrm{Fax}+$ I 5417379154

Email moniqueudell@gmail.com

\begin{abstract}
Research suggests that humans can form strong attachments to their pets, and at least some pets display attachment behaviors toward their human caretakers. In some cases, these bonds have been found to support or enhance the physical and emotional well-being of both species. Most human-animal interaction research to date has focused on adult owners, and therefore less is known about childhood pet attachment. However, there is growing evidence that pets may play an important role in the development and well-being of children, as well as adult family members. Research conducted to date suggests that child-pet relationships may be especially impactful for children who do not have stable or secure attachments to their human caretakers. However, given that human-animal interactions, including pet ownership, can also introduce some risks, there is considerable value in understanding the nature of child-pet attachments, including the potential benefits of these relationships, from a scientific perspective. The purpose of this review is to provide background and a brief overview of the research that has been conducted on childhood attachment to pets, as well as to identify areas where more research would be beneficial.
\end{abstract}

Keywords: human-animal interactions, pet ownership, attachment style, secure base, child development

\section{Introduction}

The practice of keeping pets is a common and growing phenomenon worldwide. Although the numbers and species of pets kept vary across countries and cultures, dogs and cats are arguably among the most popular, with roughly 90 million pet dogs and 94 million pet cats living in the USA alone. ${ }^{1}$ In recent years there has been a growing scientific curiosity about the impact that companion animals have on the lives, health, and psychological well-being of humans. Human-animal interaction research suggests that humans often form strong attachments to their pets. ${ }^{2,3}$ In some cases, pet ownership has been associated with greater physical and emotional well-being in both adults and children. ${ }^{4,5}$ A growing number of studies point to possible therapeutic benefits of human-animal interactions. ${ }^{6}$ It is important to note that, to date, the majority of research in this field has focused on relationships between pets and adult human owners and consequently potential benefits to children have often been extrapolated from research conducted with adults. However, children are often credited with instigating pet acquisition, and in many countries, households with children are more likely to have companion animals than households without children. ${ }^{5,7}$ Therefore, childhood pet attachment, both the psychological basis for the relationship and the impact that pets may have on child development and well-being, is an important area for further consideration. 


\section{Origins of attachment research}

The origins of attachment theory developed within ethology, with a focus on the evolutionary and biological foundations of mother-offspring relationships. The function of attachment, as a mechanism by which offspring came to seek out the proximity of their caretaker, provided opportunities for offspring to obtain food, warmth, shelter, and other resources during an especially vulnerable period of life. ${ }^{8}$ The critical nature of these attachment bonds to healthy social and cognitive development, however, was later brought to light by laboratory studies, such as those conducted by Harlow and his colleagues, starting in the 1950s. This included research on the effects of social isolation on primate behavior. For example, in one study infant rhesus macaques were separated permanently from their mothers at different ages $(60,90$, or 120 days of age) and placed in one of two housing groups: infants housed alone or in pairs. The infant monkeys in all groups showed a "protest reaction" and agitation during the first 2 days of separation. ${ }^{9}$ Following this study, similar protest reactions have been noted across a wide range of primates, ${ }^{10}$ including human children. ${ }^{11,12}$ Suomi et al also found differing post-separation behavior among the infant monkeys according to social housing conditions. ${ }^{9}$ In the week following separation, compared to monkeys housed in pairs, monkeys housed alone displayed lower levels of locomotor behavior and higher levels of self-clasping behavior and disturbance activity, such as producing screeching or cooing vocalizations, or engaging in stereotypic behavior, such as rocking. Monkeys that were reared alone from birth displayed these same behaviors at similar levels to the monkeys that were first reared with their mother, then separated and housed alone., ${ }^{9,13}$ These findings provided critical evidence that social exposure and the formation of attachment bonds early in life were important to psychological development and behavior in ways that extended beyond the acquisition of food, warmth, or other resources critical to survival.

Early research also pointed to other developmental benefits of the attachment bond. In another study, infant rhesus macaques, which had previously been imprinted onto a wire-cloth monkey replica, were placed in a strange situation known as the open-field test. ${ }^{14}$ In this test, each monkey found itself alone in a novel environment full of objects and toys that could be explored. Across 3-minute sessions, monkeys displayed strikingly different behavior in the presence and absence of the inanimate wire-cloth surrogate. Harlow found that the monkeys not only sought out contact and comfort from the wire-cloth surrogate, but could also use the surrogate as a secure base, or a point of safety from which they could explore the environment. In the absence of the wire-cloth surrogate, the monkeys emitted distress vocalizations and displayed behaviors such as freezing. ${ }^{14}$ Therefore, attachment security not only facilitated stress reduction, but also promoted exploration behaviors critical to an infant's ability to learn about the environment through experience, an important step for developing independence.

\section{Human attachment research}

Many of these same questions have since been explored within the human infant-caretaker relationship, under both experimental and naturalistic conditions. ${ }^{8}$ In 1970 , Ainsworth and Bell examined child-caretaker attachment behavior by adapting the open-field test ${ }^{14}$ into what is now known as the Strange Situation Test (SST). ${ }^{15}$ Ainsworth considered all infants to be attached to their mother; however, infants displayed various styles in how they enacted this bond. As in the non-human primate literature, a secure attachment was said to allow a child to use their caregiver as a secure base from which to explore novel environments, providing a source of comfort to retreat to in a threatening situation and facilitating a contact-exploration balance. ${ }^{8}$ Individuals with insecure attachments were not able to use their caregiver in this manner. Many decades of research established four primary styles of attachment: secure, insecure-ambivalent, insecure-avoidant, and insecure-disorganized. ${ }^{16-18}$ As seen in Table 1, these styles are based on patterns of behavior exhibited by a child toward their caregiver, specifically focused on relative rates of proximity-seeking, contact-seeking, distress, and exploration after their caretaker returns from a brief absence.

Although most children fall within one of the four main styles of attachment, with the greatest proportion displaying a secure attachment to at least one primary caregiver, ${ }^{17,18}$ in some cases children exposed to conditions of instability, deprivation, or abuse have been found to display patterns of attachment behavior that do not fit the main styles of attachment shown in Table 1. For example, researchers examined adopted children originating from the UK and adopted children who came to the UK from Romanian orphanages. ${ }^{19}$ Children in Romanian orphanages were exposed to deprived conditions which included being constrained to cots, extremely limited contact with caregivers, a lack of toys, and washing that 
Table I Definitions and criteria for the four primary styles of attachment ${ }^{16-18}$

\begin{tabular}{|c|c|c|}
\hline $\begin{array}{l}\text { Secure base } \\
\text { designation }\end{array}$ & $\begin{array}{l}\text { Attachment } \\
\text { style }\end{array}$ & Attachment style definitions \\
\hline Secure & Secure & $\begin{array}{l}\text { Child is comforted by caretaker's return after a brief absence. Child positively greets caretaker and } \\
\text { seeks to be in contact with them, returning to play and exploration soon afterward }\end{array}$ \\
\hline \multirow[t]{3}{*}{ Insecure } & $\begin{array}{l}\text { Ambivalent } \\
\text { (resistant) }\end{array}$ & $\begin{array}{l}\text { Child displays contradictory behavior in response to caretaker's return. Child may engage in excessive } \\
\text { proximity- and contact-seeking toward their caretaker while showing persistent distress and being } \\
\text { difficult to soothe }\end{array}$ \\
\hline & Avoidant & $\begin{array}{l}\text { Child avoids caretaker during reunion. Shows disinterest in caretaker's whereabouts during separation } \\
\text { and may explore whether or not caretaker is present }\end{array}$ \\
\hline & Disorganized & $\begin{array}{l}\text { Child displays contradictory behavioral patterns, undirected movements and expressions, including } \\
\text { stereotypies. Disoriented behaviors include approaching with head averted, freezing for long periods of } \\
\text { time, or displaying a dazed expression }\end{array}$ \\
\hline
\end{tabular}

consisted of being hosed down with cold water. Researchers found striking physical and cognitive differences between these children. Upon entry to the UK, children from Romanian orphanages were severely developmentally impaired compared to their UK counterparts, with half of the children 2 years of age or under scoring below the typical third percentile on height, weight, head circumference, and cognitive level. Children who came from Romanian orphanages to the UK prior to 6 months old showed a higher degree of cognitive recovery at 4 years old compared to children who stayed in the deprived conditions past 6 months of age, suggesting a sensitive period effect and highlighting the importance of early intervention for socially deprived children. ${ }^{19}$ Researchers then followed up the children at age 6 to measure attachment behavior using parental reports and an SST modified for use in the home. ${ }^{20}$ The results indicated that the pattern of behavior seen in children from Romanian orphanages did not fit the typical categorizations of attachment behavior and thus constituted a distinct behavioral pattern. This pattern, known as disinhibited attachment, is characterized by several behavioral features including a lack of differentiation in social response to adults, such as a greater likelihood to follow strangers, and a lack of parental social referencing in aversive situations. Marked disinhibited attachment was rarely observed among the within-UK adoptees and was significantly more common among the Romanian adoptees. $^{20}$ In all, the results of this research indicate that early rearing experience is strongly associated with attachment to the caregiver, and social deprivation leads to the formation of insecure and socially inappropriate attachment behavior.

Childhood attachments, including those formed when the child is an infant, are thought to be predictive of a wide range of long-term outcomes. For example, having at least one secure attachment figure has been associated with positive social interactions with future partners, ${ }^{21-23}$ decreased anxiety, ${ }^{24}$ improved higher-order cognitive processes primarily associated with activity in frontal areas of the brain, such as working memory and inhibition, ${ }^{25}$ and less conflict in interpersonal relationships, including marriage and parenting. ${ }^{24,26-28}$ Insecure attachments have been associated with increased aggression, ${ }^{29}$ increased likelihood of anxiety disorders, ${ }^{24}$ and increased inclinations toward independence (sometimes to the detriment of interpersonal relationships). ${ }^{22,28}$ Therefore, the formation of a stable secure attachment to one or more individuals in a child's life may have important behavioral, psychological, and developmental implications.

While in many cases a child's primary attachment figure is their parent or caretaker, the importance of attachment bonds to the development and social cognition of humans may explain why it is common for children to form attachments to multiple people, something that is especially likely after the age of 18 months. ${ }^{30}$ Secondary attachments are often established with other adults, or in some cases siblings. ${ }^{31}$ However, the growing literature on human-animal bonds raises important questions about whether attachment to pets could also have a beneficial impact on child development.

\section{Human-pet attachment}

In recent years, the bonds formed between humans and their pets have more frequently been regarded as attachment relationships ${ }^{32,33}$ that often benefit both the animal ${ }^{34}$ and human ${ }^{35-38}$ in terms of health and welfare outcomes. To date, the majority of this research has focused on adult human-pet attachment, and consequently attachment to pets has most commonly been evaluated through selfreport surveys, such as the Lexington Attachment to Pets Scale (LAPS), ${ }^{39}$ that are designed to assess relative 
attachment strength as opposed to the attachment style categories described in Table 1. These surveys have allowed for the evaluation of possible relationships between variables, such as the owners' perceived attachment toward their pet, and the quality of care provided to the animal or the quality of human-animal interactions experienced. $^{40-42}$

It is noteworthy that across a wide range of surveys many owners report feeling a very close attachment to their pets, sometimes reporting greater levels of attachment to their pet than toward other human members of their family. ${ }^{2,3}$ The grief that individuals report feeling at the loss of a dog is often profound and debilitating and has been equated to the loss of a child for at least some pet owners. ${ }^{43}$ The LAPS has also been used by researchers to understand how and why attachment levels may differ between different populations of owners. For example, Bagley and Gonsman found that the length of time an individual owned a pet and the more pet experience the owner had were correlated with higher attachment levels. ${ }^{32}$ Other studies have found that family dynamics, including the number of family members in the household and the number of children in the household, can influence how attached the owner reports feeling toward the pet. $^{38,40,44}$ While the human-animal attachment literature is growing rapidly, far fewer studies have focused specifically on childhood attachment to pets. While for young children, behavioral attachment tests that would place the pet in the role of a human caretaker are possible, often child-pet attachment studies have instead utilized the self-report (or parent report) method established in the adult human-animal bond literature, often looking at behavioral indicators of attachment or attachment strength instead of attachment style.

Across several studies, children have been found to exhibit at least some attachment-related behaviors toward companion animals, including protesting about separation and seeking proximity and comfort when reunited. ${ }^{7}$ Some have suggested that children with insecure attachments to human caretakers may be more primed to seek comfort and gain support from dogs, compared to humans, under stressful situations. ${ }^{45}$ Furthermore, a study by Julius et al utilized the Separation Anxiety Test (SAT) and found no correlation between children's attachment representations toward people on the SAT and their attachment representations toward their pets (assessed via questionnaire), ${ }^{46,47}$ suggesting that pets may provide social support even when children do not feel securely attached to other humans.

Therefore, while some studies looking at attachmentrelated behaviors in humans with respect to their dog have been conducted (looking at behaviors such as separation distress and greeting upon reunion), ${ }^{7}$ assessments of human attachment toward dogs have typically been conducted via survey, a method typical for assessing humanhuman attachment relationships in older children and adults, but different from the kinds of behavioral attachment tests more commonly conducted with human infants and their caretakers. Conversely, studies of dog attachment toward human caretakers have utilized the behavioral attachment tests developed in the non-human primate and human infant literature. ${ }^{14,48}$ Therefore, conducting comparable behavioral tests that would more directly evaluate child-pet attachment, as a direct comparison to the childcaretaker attachment literature (taking the age of the child into account to determine what the most appropriate comparative assessment would be), may be an interesting avenue for future research.

\section{Child-pet attachment: family and social factors}

One factor that seems to have a significant impact on the strength of children's attachment to pets is the availability of people in the child's life. For example, a study conducted in the UK using the validated CENSHARE Pet Attachment Scale found strong evidence that single children selfreported having stronger attachments to their favorite family pet than children with siblings. ${ }^{49}$ Another study conducted in Australia by Bodsworth and Coleman demonstrated that children being raised by a single parent were more strongly attached to their pet dog than children being raised in a two-parent family (as measured by parents' judgments of their children's level of attachment using a previously validated Companion Animal Bonding Scale). ${ }^{50}$

In addition, children in the early childhood group (ages 3-6) who were being raised by a single parent had significantly stronger attachments to the family dog than the early childhood group being raised in a two-parent family, and a trend toward stronger attachment in the single-parent group for the middle childhood group (ages 7-12). ${ }^{50}$

Several other studies have also found interesting effects of age on the strength of children's attachment to pets. Westgarth et al found evidence that in families with multiple children, the youngest child typically had the strongest attachment to their family pet. ${ }^{49}$ A study from Croatia, which utilized child self-reports on a Child Pet Attachment Scale questionnaire, concluded that the strength of children's attachment to their pets gradually 
decreased as they grew older. ${ }^{51}$ Additional evidence comes from a review article by Jalongo, suggesting that children typically score higher than adults on measures of the strength of their attachment to dogs. ${ }^{7}$

The relationship between bonding opportunities with humans, and the strength of pet attachment, may be even stronger in cases of childhood neglect or abuse. For example, in a study of 160 children who had experienced abuse, neglect, or traumatic loss, reports of a secure attachment to a pet, especially a dog or cat, were four times more likely than a secure attachment to their human caregiver. ${ }^{46,47}$ Further research on the impact of childhood neglect on attachments to companion animals has been conducted only in adult populations. One study found that among a sample of college students, women who reported having experienced neglect as children reported moderately stronger present-day attachments to companion animals on the Pet Attachment and Life Impact Scale (PALS) than did women who had not been neglected as children (this correlation was not found among male participants, who also reported slightly lower levels of attachment to pets overall). ${ }^{52} \mathrm{It}$ is worth noting that gender differences in reported attachment to companion animals were found in the sample of college students aged 18 62 years, ${ }^{52}$ and in at least one other study, ${ }^{51}$ although not all studies have reported gender differences. ${ }^{49}$

Similarly, several studies of adults have evaluated the relationship between companion animal attachment strength and experiences of dissociation, defined as "a separation between processes that are normally integrated, such as events, emotions, and memories," which may result from severe trauma (especially childhood abuse).$^{53}$ For example, a study of college students by Brown and Katcher found that the adult subjects' levels of dissociation were positively correlated to their attachments to companion animals. ${ }^{54}$ The results of a study by Barlow et al supported that finding, with two groups of college students identified as having low versus high levels of dissociation; they also found that a separate sample of women with clinically diagnosed dissociative identity disorder (DID), a condition where an individual presents with two or more distinct personality states or identities, had significantly stronger attachments to companion animals than both of the groups of college students, as measured by the Pet Attachment and Life Impact Scale (PALS). No men with DID took part in the study. ${ }^{53}$ Assuming that dissociation and DID may be associated with childhood abuse, the evidence suggests that adults who experienced abuse as children may be more likely to develop stronger attachments to companion animals, possibly as a result of unmet needs they had as children for healthy relationships with humans. However, no studies to date have evaluated the strength of the attachments that victims of child abuse exhibit toward companion animals while the victims are still children, or to what extent a strong attachment to a pet may buffer negative effects or aid in therapeutic interventions for child abuse survivors. These may be important areas of study in the future.

\section{Child-dog attachment: canine behavioral factors}

Research indicates that the circumstances of children's lives and the people around them are not the only factors influencing children's attachment toward their dogs. Jalongo asserts that a child's attachment to their dog is likely to be stronger when they are involved with the dog's care and understand its needs. ${ }^{7}$ Hall et al provided further explanation for this correlation when they demonstrated that children feel stronger attachments to dogs that are responsive to their social communicative cues. ${ }^{55}$ In their study, 99 children aged 7-12 years participated in a gesture-following test with their dog to measure the dog's ability to utilize the child's pointing gesture to choose the correct can in a two-object choice task. Success with the gesture-following test was positively correlated with the strength of the child's attachment toward their dog (as measured by child self-reports on the LAPS, completed prior to the gesture-following test). They also found that dog-child dyads scored higher on the gesture-following test when the child was responsible for the dog's care at home (ie, feeding, walking, and grooming). However, they found no evidence that stronger feelings of attachment toward the dog was directly related to their involvement in the dog's care at home. Rather, it seemed that caring for the dog made the dog more responsive to the child's communicative cues, and the greater responsiveness made the child feel more attached to the dog. ${ }^{55}$ Jalongo also suggests that mutual responsiveness between the child and dog builds stronger attachments between them, as do more shared activities and more time spent together. ${ }^{7}$

The hormone oxytocin may also play a role in the quality of the human-dog relationship. ${ }^{56}$ Research has suggested that owners whose dogs gaze at them for longer periods of time during experimental interaction sessions have higher oxytocin levels and also report a more positive relationship with their dogs compared to owners whose dogs spend less time gazing at them. ${ }^{56,57}$ To date, no studies have examined the role of oxytocin in relationships 
between children and dogs, or humans and pets other than dogs, although these would be interesting areas of future study, as oxytocin is an important component of social bonds in many species, starting from birth. ${ }^{58}$

\section{Potential benefits}

Relationships between pets and people have been shown to have at least some important physiological and psychological benefits. While many of these effects have been reported in studies focused on adult participants, research conducted with children has shown similar trends. For example, in adults, the role of pet ownership (particularly dog ownership) in reducing the risk of cardiovascular disease has been well documented. ${ }^{59}$ Another study found that attachment to pets was related to lower systolic blood pressure. ${ }^{60} \mathrm{~A}$ more recent finding indicates that there is a correlation between level of attachment (as measured by the LAPS) and reduction in heart rate among cat owners after interacting with their cats. ${ }^{61}$ The presence of, or even thinking about, a pet dog has been found to result in the secure base effect and lower blood pressure levels during a difficult cognitive task designed to cause elevated stress when compared with controls. Importantly, in this study, the ability of pets to function as a secure base and safe haven for their owners was related to the security of the attachment relationship reported by the owner. ${ }^{62}$ Animal-assisted activities have also been shown to be effective in treating and managing depression. ${ }^{63}$

Research on relationships between children and their pet dogs, and relationships between children and animals that they engage with as part of animal-assisted interventions (AAIs), have both demonstrated that companion animals are a source of physical and emotional support for children., ${ }^{4,5}$ People have an innate need for physical touch from others, but sometimes people are not comfortable being touched by, or touching, other people, and in those cases dogs and other animals may provide the safest, most intimate, and most comforting physical touch that people need to develop social connection. ${ }^{45,47,64}$ Dogs are perceived to be accepting, non-judgmental, and stable sources of unconditional love. ${ }^{4,7,52,64,65}$ In addition, the perception that dogs are more forgiving than people, present their feelings authentically in the moment, ${ }^{7,64}$ and do not care about a person's history can be grounding and calming. ${ }^{64}$ Studies have shown that interactions with animals can cause children's blood pressure and heart rate to decrease, ${ }^{47,64,65}$ and for those recovering from trauma the presence of animals may be especially beneficial for lowering their state of hyperarousal. ${ }^{64}$

As both pet ownership and AAIs have grown more common, evaluations of child-animal interactions across a variety of settings have begun to take place. While some benefits of the relationship between a child and companion animal may be similar across contexts, other factors may vary depending on the type of relationship and frequency of interaction (eg, a pet living in the home versus limited visits to a therapy animal). While it seems likely that stronger attachment relationships would form with owned animals, it should be noted that more research in this area is needed and this assumption warrants empirical testing as more scientifically based AAIs are developed.

\section{Potential benefits of childhood attachment to animals in the home}

In cases when humans may not be available, pet dogs can be relied upon to be available to provide comfort and security. ${ }^{4,5,7,50}$ For children who have a hard time trusting people, including members of their family, it may be much easier for them to readily trust a dog. ${ }^{45}$ Pets may also provide valuable companionship for children experiencing conflict among family members. For instance, a study using the Network of Relationships Inventory found that 12-year-old children experienced less conflict with their pets compared to siblings and experienced greater relationship satisfaction with their pets than with their siblings. ${ }^{66}$ There is also some evidence of a correlation between children's level of attachment to their pets and quality of life, as well as overall satisfaction with life. ${ }^{67}$

Many researchers have also asserted that pet dogs have a significant impact on children's development by providing an opportunity for the child to care for a dependant. Having the opportunity to care for a dependant fulfills the child's need to feel important and needed, and to have a purpose. $^{47}$ A study on survivors of child sexual abuse stated that companion animals sometimes provide a reason for child abuse survivors to live. ${ }^{4}$ Another study indicated that caring for a pet was "positively correlated with feelings of importance, social competence and self-esteem." 51 Bodsworth and Coleman suggest that when a "preadolescent perceives that [they have] successfully cared for the dependent animal, this in turn leads to feelings of achievement" and helps them to develop their self-concept. ${ }^{50}$ Caring for a dog can teach a child responsibility and give them a sense of capability. ${ }^{50,64}$ Nancy Parish-Plass, a practitioner of animal-assisted psychotherapy, argues that 
in both family contexts and therapeutic contexts, interacting and developing a relationship with an animal helps the child to feel accepted and trusted, and gives them the empowering opportunity to be in control, which for victims of abuse in particular could be very impactful given that they may have developed a pervasive feeling of helplessness in their lives. ${ }^{64}$

\section{Potential benefits of childhood attachment to animals outside the home}

For children who have significant unmet social needs, such that it has taken a toll on their social development, there may be great potential in intentionally utilizing dogs in therapeutic approaches. As previously discussed in the section "Human attachment research", deprived and abused children often have setbacks in their social development, including significant impairments in their abilities to empathize, to accurately interpret others' intentions, and to appropriately regulate and express their emotions. ${ }^{64}$ There seems to be strong potential in utilizing dogs to help with the treatment of neglected and abused children, given the evidence that they may be more likely to trust and develop stronger attachments to dogs, ${ }^{5,45}$ and that pet attachment promotes healthy social development, social competence, increased social interaction, improved social communication, and social play behavior. ${ }^{5}$ Companion animals can help children to learn to express and understand non-verbal communication and decipher intentions, which leads to improved emotional understanding and expression. $^{64}$

Some child-focused interventions looking at potential benefits of developing attachment to animals have shown great promise. For example, Balluerka et al conducted a study with 46 adolescents who had traumatic childhood experiences and at the time of the study exhibited mental health issues and resided in residential care facilities in Spain. ${ }^{68}$ The participants, aged $12-17$ years, were divided into two groups, with 25 adolescents comprising a control group and 21 adolescents participating in an animalassisted therapy (AAT) program on 2 days per week for 12 weeks. The AAT program primarily involved interventions with a horse (of their choice) and also with a therapy $\mathrm{dog}$, as well as occasional guided interactions with cats, goats, sheep, pigs, and chickens. Using the CaMir-R questionnaire, which measures participants' mental representations of attachment, the researchers found that the participants in the AAT group had higher scores in the dimension of secure attachment compared to both their baseline scores and the control group. These results demonstrate that the development of a therapeutically based relationship with an animal has the potential to "reformulate [adolescents'] style of attachment and social and emotional functioning."68 No studies to date have evaluated the impacts of acquiring/owning a pet on similar measures of mental representations of attachment in youth who have experienced abuse, neglect, or trauma, but the aforementioned positive impacts that dogs can have in children's lives, especially when the children have unmet needs for healthy social interactions with people, suggest that this would be a worthwhile area for further research. However, to date, many of the benefits derived from human-animal interactions have not been contingent upon ownership. Some studies have suggested that it is the strength of the attachment between a child and a dog, not ownership, that is a stronger determinant of potential benefits. $^{5}$

\section{Potential risks}

Despite the supported and hypothesized benefits associated with attachment to pets, it is also important to consider potential risks associated with human-animal interactions and bonds. One survey-based study found that elderly adults with higher levels of attachment to their pets reported higher levels of depression compared to elderly adults who had lower levels of attachment toward their pets. $^{69}$ Individuals who reported stronger attachments to their pets reported grieving more strongly upon their pet's death than those with less strong attachments. ${ }^{70}$ Those with greater attachment anxiety also experienced more severe grief upon loss of their pet. ${ }^{70}$ Attachment anxiety is characterized by disproportionate worry over the loss of or rejection by an attachment figure. As the authors of this study explain, this finding can be understood in the context of Bowlby's work, which suggests that adults with anxious attachments will exhibit more difficulty with regulating emotions during the loss of an attachment figure. ${ }^{70}$ Another study found a similar relationship between attachment and grief over the loss of an assistance dog, ${ }^{43}$ a factor that may be increasingly more relevant for children as the rate of placement of assistance dogs with children increases (eg, autism assistance dogs). However, despite experiencing this grief, many owners reported that they did not regret the strength of the bond they had shared with their dogs. ${ }^{43}$ While these factors have not been studied with children, they are important considerations for evaluating the overall psychological outcomes of 
childhood pet attachment, especially given that the first experience many children have with death is through the death of a pet. Moreover, the psychological risks of pet loss for children who have experienced abuse, neglect, or trauma may be even greater. Some have suggested that the grief response to the loss of a pet can be comparable to the loss of a human loved one, and research has shown that people with traumatic childhoods are at risk for abnormally severe grief responses to the loss of a person, including "negative physical and psychological outcomes such as serious illness, suicidal ideation and impairments in quality of life." 4

Other potential risks of child-animal interactions include adverse effects of allergies and increased risk of illness due to exposure or cohabitation with animals. For example, while the role of pets in transmitting pathogens is relatively small, the populations most at risk include children under the age of 5 years, ${ }^{71}$ making such considerations of particular importance when discussing relationships between children and their pets. Allergies to pets are another consideration. For instance, increased visits to healthcare providers and other associated costs for asthma treatment among adult dog-owners who have allergies to dogs results in an increase of \$0.5 to \$1 million per year in healthcare costs in the USA. ${ }^{72}$ Another study demonstrated that indirect exposure to cat allergens, via other students, increased asthma symptoms in children with asthma who were allergic to cats but did not have a cat at home. ${ }^{73}$ Although there has been some debate in the literature regarding whether exposure to pets increases children's likeliness to develop allergies to pets, it is generally agreed that exposure to pets in infancy either decreases or does not change the risk of pet allergies later in life. ${ }^{74}$ Therefore, pet-related illness is a complex issue and in some cases animal exposure or ownership may provide benefits to some and pose risks to others.

Another risk of child-animal interactions is the risk of injuries and bites. Overall, approximately $1.5 \%$ of the US population is affected by dog bites each year. ${ }^{75}$ Children under the age of 15 are among the highest risk groups for dog bites, and within this group, the incidence of dog bites increases in children between the ages of 5 and 9 years. ${ }^{76}$ However, it should be noted that while the presence of a dog in the household increases the risk that a dog bite will occur, there has been a decline in the incidence of dog bites among children in recent years. ${ }^{75}$ While no research has explored the role of attachment security with respect to safety-related concerns, there is evidence that initiatives promoting better education about child-pet interactions and an increased focus on establishing positive bonds between pets and household members may help to reduce the risks of injuries and bites. ${ }^{77,78}$ Meints et al suggest that the misinterpretation of dog body language is a major cause of dog bites, and they advocate for education for both children and parents to better understand dog signaling to help reduce the risks associated with pet ownership. $^{79}$

\section{Conclusion}

While the importance of stable secure attachments in childhood has been recognized for many decades, only recently have attachments to pets been considered as a possible part of this equation. The research would suggest that for both adults and children, attachment to pets (especially dogs and cats) can provide social support and may contribute to a wide range of physical and psychological benefits. ${ }^{4,7,52,64,65}$ Age of the child may be an important consideration when evaluating the degree of impact or kind of support one might expect from such a relationship. For example, while a slightly higher risk of illness or injury may exist before the age of 9 years, ${ }^{76}$ in at least some cases risks appear to be lessened when the timing of first exposure and better education about safe interactions with animals are considered. ${ }^{74,77,78}$ Therefore, attachments to pets in young children may still provide benefits, assuming that proper precautions, and supervision, are provided. Conversely, older children may be more likely to provide care or engage in joint activities with their pets, which could increase the likelihood that they become the caretaker in the attachment equation. This could have its own set of outcomes and potential benefits, which could be similar to or different from the support that younger children experience through attachment to their pets. While it seems likely that during the period when initial attachments to human caretakers are occurring, early in infancy, direct or independent interactions with pets may play a more limited role or even introduce more potential for risk (eg, allergies, injury) than benefit, more research is needed to understand how the risks and benefits of child-pet interaction and attachment change across developmental stages.

Multiple factors are associated with stronger child-dog attachment relationships, including the availability of adult human attachment figures, number and birth order of siblings, history of neglect or abuse, and how responsive the dog is to the child's actions. While there is still much 
research to be done in this area, studies conducted to date seem to suggest that a solid foundation for further scientific discovery in this area exists, and that child-pet relationships may be an area of growing applied importance given the large and increasing presence of pets living in homes with children around the world. In addition, the growing number of AATs and interventions aimed at children add to the critical need for more scientific research aimed at this population specifically. More research exploring the psychological underpinnings and mechanisms associated with childhood attachment to pets will also facilitate a deeper understanding of why and how these relationships form, and how similar or different they may be to attachment relationships shared between children and other humans.

\section{Disclosure}

The authors report no conflicts of interest in this work.

\section{References}

1. American Pet Products Association. Available from: https://american petproducts.org/. Accessed February 1, 2019.

2. Barker S, Barker R. The human-canine bond: closer than family ties? J Ment Health Couns. 1988;10(1):46-56.

3. Cohen SP. Can pets function as family members? West J Nurs Res. 2002;24(6):621-638. doi:10.1177/019394502320555386

4. Taylor SC, Breen LJ. Exploring pet loss for survivors of child sexual abuse: a hitherto uncharted terrain of trauma impact and recovery. Child Abuse Rev. 2014;23:353-360. doi:10.1002/car.2279

5. Purewal R, Christley R, Kordas K, et al. Companion animals and child/adolescent development: a systematic review of the evidence. Int J Environ Res Public Health. 2017;14(234):1-25. doi:10.3390/ ijerph14030234

6. Polheber JP, Matchock RL. The presence of a dog attenuates cortisol and heart rate in the Trier Social Stress Test compared to human friends. $J$ Behav Med. 2014;37(5):860-867. doi:10.1007/s10865-013-9546-1

7. Jalongo MR. An attachment perspective on the child-dog bond: interdisciplinary and international research findings. Early Child Educ J. 2015;43:395-405. doi:10.1007/s10643-015-0687-4

8. Bowlby J. The nature of the child's tie to his mother. Int $J$ Psychoanal. 1958;39:350-373.

9. Suomi SJ, Collins ML, Harlow HF. Effects of permanent separation from mother on infant monkeys. Dev Psychol. 1973;9(3):376-384. doi: $10.1037 / \mathrm{h} 0034896$

10. Suomi SJ, Collins ML, Harlow HF, Ruppenthal GC. Effects of maternal and peer separations on young monkeys. J Child Psychol Psychiatry. 1976;17(2):101-112. doi:10.1111/j.1469-7610.1976.tb00382.x

11. Ainsworth MDS, Blehar MC, Waters E, Wall S. Patterns of Attachment: a Psychological Study of the Strange Situation. Hillsdale (NJ): Lawrence Erlbaum Associates; 1978.

12. Ainsworth MDS, Bowlby J. An ethological approach to personality development. Am Psychol. 1991;46(4):333-341. doi:10.1037/0003066X.46.4.333

13. Cross HA, Harlow HF. Prolonged and progressive effects of partial isolation on the behavior of Macaque monkeys. J Exp Res Pers. 1965;1(1):39-49.
14. Harlow HF. The nature of love. Am Psychol. 1958;13:673-685. doi: $10.1037 / \mathrm{h} 0047884$

15. Ainsworth MDS, Bell SM. Attachment, exploration, and separation: illustrated by the behavior of one-year-olds in a strange situation. Child Dev. 1970;41:49-67. doi:10.2307/1127388

16. Bowlby J. Attachment and Loss. 2nd ed. New York (NY): Basic Books; 1982.

17. Ainsworth MDS. Patterns of infant-mother attachments: antecedents and effects on development. Bull N Y Acad Med. 1985;61(9):771-791.

18. Main M, Solomon J. Procedures for identifying infants as disorganized/disoriented during the ainsworth strange situation. In: Attachment in the Preschool Years: Theory, Research, and Intervention. Chicago, IL: University of Chicago Press; 1990:121160.

19. Rutter M. Developmental catch-up, and deficit, following adoption after severe global early privation. J Child Psychol Psychiatry. 1998;39(4):465-476. doi:10.1017/S0021963098002236

20. Rutter M, Colvert E, Kreppner J, et al. Early adolescent outcomes for institutionally-deprived and non-deprived adoptees. I: disinhibited attachment. $J$ Child Psychol Psychiatry. 2007;48(1):17-30. doi:10.1111/j.1469-7610.2006.01688.x

21. Simpson JA. Influence of attachment styles on romantic relationships. $J$ Pers Soc Psychol. 1990;59(5):971-980. doi:10.1037/0022-3514.59.5.971

22. Maccoby EE. The role of parents in the socialization of children: an historical overview. Dev Psychol. 1992;28(6):1006-1017. doi:10.1037/0012-1649.28.6.1006

23. Kobak RR, Hazan C. Attachment in marriage: effects of security and accuracy of working models. J Pers Soc Psychol. 1991;60(6):861869. doi:10.1037/0022-3514.60.6.861

24. Bögels SM, Brechman-Toussaint ML. Family issues in child anxiety: attachment, family functioning, parental rearing and beliefs. Clin Psychol Rev. 2006;26(7):834-856. doi:10.1016/j.cpr.2005.08.001

25. Bernier A, Beauchamp MH, Carlson SM, Lalonde G. A secure base from which to regulate: attachment security in toddlerhood as a predictor of executive functioning at school entry. Dev Psychol. 2015;51(9):1177-1189. doi:10.1037/dev0000032

26. Kirkpatrick LA, Davis KE. Attachment style, gender, and relationship stability: a longitudinal analysis. J Pers Soc Psychol. 1994;66 (3):502-512. doi:10.1037/0022-3514.66.3.502

27. van IJzendoorn MH. Adult attachment representations, parental responsiveness, and infant attachment: a meta-analysis on the predictive validity of the adult attachment interview. Psychol Bull. 1995;117(3):387-403. doi:10.1037/0033-2909.117.3.387

28. Belsky J. Attachment, mating, and parenting. Hum Nat. 1997;8 (4):361-381. doi:10.1007/BF02913039

29. Lyons-Ruth K. Attachment relationships among children with aggressive behavior problems: the role of disorganized early attachment patterns. J Consult Clin Psychol. 1996;64(1):64-73. doi:10.1037/ 0022-006X.64.1.64

30. Schaffer HR, Emerson PE. The development of social attachments in infancy. Monogr Soc Res Child Dev. 1964;29(3):1-77. doi:10.2307/ 1165727

31. Stewart RB. Sibling attachment relationships: child-infant interactions in the strange situation. Dev Psychol. 1983;19(2):192-199. doi:10.1037/0012-1649.19.2.192

32. Bagley DK, Gonsman VL. Pet attachment and personality type. Anthrozoos. 2005;18(1):28-42. doi:10.2752/089279305785594333

33. Kurdek LA. Pet dogs as attachment figures. J Soc Pers Relat. 2008;25(2):247-266. doi:10.1177/0265407507087958

34. Serpell J, Barrett P. The Domestic Dog: Its Evolution, Behavior and Interactions with People. New York (NY): Cabridge University Press; 1995.

35. Garrity TF, Stallones L, Marx MB, Johnson TP. Pet ownership and attachment as supportive factors in the health of the elderly. Anthrozoos. 1989;3(1):35-44. doi:10.2752/089279390787057829 
36. Rooney NJ, Bradshaw JW. An experimental study of the effects of play upon the dog-human relationship. Appl Anim Behav Sci. 2002;75 (2):161-176. doi:10.1016/S0168-1591(01)00192-7

37. Bennett PC, Rohlf VI. Owner-companion dog interactions: relationships between demographic variables, potentially problematic behaviours, training engagement and shared activities. Appl Anim Behav Sci. 2007;102(1-2):65-84. doi:10.1016/j.applanim.2006.03.009

38. Meyer I, Forkman B. Dog and owner characteristics affecting the dog-owner relationship. $J$ Vet Behav. 2014;9(4):143-150. doi:10.1016/j.jveb.2014.03.002

39. Johnson TP, Garrity TF, Stallones L. Psychometric evaluation of the Lexington Attachment to Pets Scale (LAPS). Anthrozoos. 1992;5 (3):160-175. doi:10.2752/089279392787011395

40. Marinelli L, Adamelli S, Normando S, Bono G. Quality of life of the pet dog: influence of owner and dog's characteristics. Appl Anim Behav Sci. 2007;108(1-2):143-156. doi:10.1016/j.applanim.2006.11.018

41. Helms TD, Bain MJ. Evaluation of owner attachment to dogs on the basis of whether owners are legally considered guardians of their pets. J Am Vet Med Assoc. 2009;234(7):896-900. doi:10.2460/ javma.234.7.896

42. Mariti C, Ricci E, Carlone B, Moore JL, Sighieri C, Gazzano A. Dog attachment to man: a comparison between pet and working dogs. $J$ Vet Behav. 2013;8(3):135-145. doi:10.1016/j.jveb.2012.05.006

43. Kwong MJ, Bartholomew K. "Not just a dog": an attachment perspective on relationships with assistance dogs. Attach Hum Dev. 2011;13(5):421-436. doi:10.1080/14616734.2011.584401

44. Kubinyi E, Turcsán B, Miklósi Á. Dog and owner demographic characteristics and dog personality trait associations. Behav Processes. 2009;81(3):392-401. doi:10.1016/j.beproc.2009.04.004

45. Beetz A, Julius H, Turner D, Kotrschal K. Effects of social support by a dog on stress modulation in male children with insecure attachment. Front Psychol. 2012;3(352):1-9. doi:10.3389/ fpsyg.2012.00352

46. Julius H, Beetz AM, Niebergall $\mathrm{K}$ Breaking the transmission of insecure attachment relationships. Special session presented at: The 12th International Conference on Human-Animal Interactions (IAHAIO); July; 2010; Stockholm, Sweden.

47. Julius H, Beetz A, Kotrschal K, Turner D, Uvnäs-Moberg K. Attachment to Pets: an Integrative View of Human-Animal Relationships with Implications for Therapeutic Practice. Cambridge (MA): Hogrefe; 2013.

48. Thielke LE, Rosenlicht G, Saturn SR, Udell MAR. Nasally-administered oxytocin has limited effects on owner-directed attachment behavior in pet dogs (canis lupus familiaris). Front Psychol. 2017;8:1699. doi:10.3389/fpsyg.2017.01699

49. Westgarth C, Boddy LM, Stratton G, et al. Pet ownership, dog types and attachment to pets in 9-10 year old children in Liverpool, UK. BMC Vet Res. 2013;9(102):1-10. doi:10.1186/1746-6148-9-18

50. Bodsworth W, Coleman GJ. Child-companion animal attachment bonds in single and two-parent families. Anthrozoos. 2001;14 (4):216-223. doi:10.2752/089279301786999391

51. Vidovic V, Stetic VV, Bratko D. Pet ownership, type of pet and socioemotional development of school children. Anthrozoos. 1999;12 (4):211-217. doi:10.2752/089279399787000129

52. Barlow MR, Hutchinson CA, Newton K, Grover T, Ward L. Childhood neglect, attachment to companion animals, and stuffed animals as attachment objects in women and men. Anthrozoos. 2012;25(1):111-119. doi:10.2752/175303712X13240472427159

53. Barlow MR, Cromer LD, Caron HP, Freyd JJ. Comparison of normative and diagnosed dissociation on attachment to companion animals and stuffed animals. Psychol Trauma. 2012;4(5):501-506. doi:10.1037/a0028134

54. Brown SE, Katcher AH. The contribution of attachment to pets and attachment to nature to dissociation and absorption. Dissociation. 1997;10(2):125-129.
55. Hall NJ, Liu J, Kertes DA, Wynne CDL. Behavioral and self-report measures influencing children's reported attachment to their dog. Anthrozoos. 2016;29(1):137-150. doi:10.1080/08927936.2015.1088683

56. Nagasawa M, Kikusui T, Onaka T, Ohta M. Dog's gaze at its owner increases owner's urinary oxytocin during social interaction. Horm Behav. 2009;55(3):434-441. doi:10.1016/j.yhbeh.2008.12.002

57. Handlin L, Hydbring-Sandberg E, Nilsson A, Ejdebäck M, Jansson A, Uvnäs-Moberg K. Short-term interaction between dogs and their owners: effects on oxytocin, cortisol, insulin and heart rate: an exploratory study. Anthrozoos. 2011;24(3):301-315. doi:10.2752/ 175303711X13045914865385

58. Carter CS, Grippo AJ, Pournajafi-Nazarloo H, Ruscio MG, Porges SW. Oxytocin, vasopressin and sociality. Prog Brain Res. 2008;170:331-336.

59. Arhant-Sudhir K, Arhant-Sudhir R, Sudhir K. Pet ownership and cardiovascular risk reduction: supporting evidence, conflicting data and underlying mechanisms. Clin Exp Pharmacol Physiol. 2011;38 (11):734-738. doi:10.1111/j.1440-1681.2011.05583.x

60. Vormbrock JK, Grossberg JM. Cardiovascular effects of human-pet dog interactions. J Behav Med. 1988;11(5):509-517. doi:10.1007/ BF00844843

61. Dinis FABSG, Martins TLF. Does cat attachment have an effect on human health: a comparison between owners and volunteers. Pet Behav Sci. 2016;1:1-12. doi:10.21071/pbs.v0i1.3986

62. Zilcha-Mano S, Mikulincer M, Shaver PR. Pets as safe havens and secure bases: the moderating role of pet attachment orientations. $J$ Res Pers. 2012;46(5):571-580. doi:10.1016/j.jrp.2012.06.005

63. Souter MA, Miller MD. Do animal-assisted activities effectively treat depression: a meta-analysis. Anthrozoos. 2007;20(2):167-180. doi:10.2752/175303707X207954

64. Parish-Plass N. Animal-assisted therapy with children suffering from insecure attachment due to abuse and neglect: a method to lower the risk of intergenerational transmission of abuse? Clin Child Psychol Psychiatry. 2008;13(1):7-30. doi:10.1177/1359104507086338

65. Beetz A, Uvnäs-Moberg K, Julius H, Kotrschal K. Psychosocial and psychophysiological effects of human-animal interactions: the possible role of oxytocin. Front Psychol. 2012;3(234):1-15. doi:10.3389/ fpsyg.2012.00234

66. Cassels MT, White N, Gee N, Hughes C. One of the family? Measuring young adolescents' relationships with pets and siblings. J Appl Dev Psychol. 2017;49:12-20. doi:10.1016/j.appdev.2017.01.003

67. Marsa-Sambola F, Muldoon J, Williams J, Lawrence A, Connor M, Currie C. The short attachment to pets scale (SAPS) for children and young people: development, psychometric qualities and demographic and health associations. Child Indic Res. 2016;9(1):111-131. doi:10.1007/s12187-015-9303-9

68. Balluerka N, Muela A, Amiano N, Caldentey MA. Influence of animal-assisted therapy (AAT) on the attachment representations of youth in residential care. Child Youth Serv Rev. 2014;42:103-109. doi:10.1016/j.childyouth.2014.04.007

69. Miltiades H, Shearer J. Attachment to pet dogs and depression in rural older adults. Anthrozoos. 2011;24(2):147-154. doi:10.2752/ 175303711X12998632257585

70. Field NP, Orsini L, Gavish R, Packman W. Role of attachment in response to pet loss. Death Stud. 2009;33(4):334-355. doi:10.1080/ 07481180802705783

71. Stull JW, Brophy J, Weese JS. Reducing the risk of pet-associated zoonotic infections. CMAJ. 2015;187(10):736-743. doi:10.1503/ cmaj. 141020

72. Ownby DR. Pet dander and difficult-to-control asthma: the burden of illness. Allergy Asthma Proc. 2010;31(5):381-384. doi:10.2500/ aap.2010.31.3389

73. Almqvist C, Wickman M, Perfetti L, et al. Worsening of asthma in children allergic to cats, after indirect exposure to cat at school. Am J Respir Crit Care Med. 2001;163(3):694-698. doi:10.1164/ajrccm.163.3.2006114 
74. Ownby D, Johnson CC. Recent understandings of pet allergies F1000Res. 2016;27:5.

75. Gilchrist J, Sacks JJ, White D, Kresnow M-J. Dog bites: still a problem? Inj Prev. 2008;14(5):296-301. doi:10.1136/ip.2007.016220

76. Overall KL, Love M. Dog bites to humans: demography, epidemiology, injury, and risk. J Am Vet Med Assoc. 2001;218(12):1923-1934. doi:10.2460/javma.2001.218.1923

77. Spiegel IB. A pilot study to evaluate an elementary school-based dog bite prevention program. Anthrozoos. 2000;13(3):164-173. doi:10.2752/ 089279300786999789
78. Chapman S, Cornwall J, Righetti J, Sung L. Preventing dog bites in children: randomized controlled trial of an educational intervention. $B M J$. 2000;320(7248):1512-1513. doi:10.1136/bmj.320. 7248.1512

79. Meints K, Brelsford V, De Keuster T. Teaching children and parents to understand dog signaling. Front Vet Sci. 2018;5:257. doi:10.3389/ fvets. 2018.00040

\section{Publish your work in this journal}

Psychology Research and Behavior Management is an international, peer-reviewed, open access journal focusing on the science of psychology and its application in behavior management to develop improved outcomes in the clinical, educational, sports and business arenas. Specific topics covered in the journal include: Neuroscience, memory and decision making; Behavior modification and management; Clinical applications; Business and sports performance management; Social and developmental studies; Animal studies. The manuscript management system is completely online and includes a very quick and fair peer-review system, which is all easy to use. Visit http://www. dovepress.com/testimonials.php to read real quotes from published authors. 